NBER WORKING PAPER SERIES

\title{
MONOPOLY AND THE INCENTIVE TO INNOVATE WHEN ADOPTION INVOLVES SWITCHOVER DISRUPTIONS
}

\author{
Thomas J. Holmes \\ David K. Levine \\ James A. Schmitz, Jr. \\ Working Paper 13864 \\ http://www.nber.org/papers/w13864
}

\author{
NATIONAL BUREAU OF ECONOMIC RESEARCH \\ 1050 Massachusetts Avenue \\ Cambridge, MA 02138 \\ March 2008
}

The views expressed herein are solely those of the authors and do not represent the views of the Federal Reserve Bank of Minneapolis or the Federal Reserve System. Holmes acknowledges research support from NSF Grant SES-05-51062. Levine acknowledges NSF Grant SES-03-14713. We have benefited from the comments of Erzo Luttmer on an earlier draft. The views expressed herein are those of the author(s) and do not necessarily reflect the views of the National Bureau of Economic Research.

NBER working papers are circulated for discussion and comment purposes. They have not been peerreviewed or been subject to the review by the NBER Board of Directors that accompanies official NBER publications.

(C) 2008 by Thomas J. Holmes, David K. Levine, and James A. Schmitz, Jr.. All rights reserved. Short sections of text, not to exceed two paragraphs, may be quoted without explicit permission provided that full credit, including $(\odot)$ notice, is given to the source. 
Monopoly and the Incentive to Innovate When Adoption Involves Switchover Disruptions

Thomas J. Holmes, David K. Levine, and James A. Schmitz, Jr.

NBER Working Paper No. 13864

March 2008

JEL No. L10,L12

\begin{abstract}
$\underline{\text { ABSTRACT }}$
When considering the incentive of a monopolist to adopt an innovation, the textbook model assumes that it can instantaneously and seamlessly introduce the new technology. In fact, firms often face major problems in integrating new technologies. In some cases, firms have to (temporarily) produce at levels substantially below capacity upon adoption. We call such phenomena switchover disruptions, and present extensive evidence on them. If firms face switchover disruptions, then they may temporarily lose some unit sales upon adoption. If the firm loses unit sales, then a cost of adoption is the foregone rents on the sales of those units. Hence, greater market power will mean higher prices on those lost units of output, and hence a reduced incentive to innovate. We introduce switchover disruptions into some standard models in the literature, show they can overturn some famous results, and then show they can help explain evidence that firms in more competitive environments are more likely to adopt technologies and increase productivity.
\end{abstract}

Thomas J. Holmes

Department of Economics

University of Minnesota

1035 Heller Hall

271 19th Avenue South

Minneapolis, MN 55455

and NBER

holmes@umn.edu

David K. Levine

Washington University

Department of Economics

Campus Box 1208

St. Louis, MO 63130-4899

and NBER

david@dklevine.com
James A. Schmitz, Jr.

Research Dept.

Federal Reserve Bank of Minneapolis

90 Hennepin Ave., PO Box 291

Minneapolis, MN 55480

jas@ res.mpls.frb.fed.us 


\section{Introduction}

Consider the incentive of a firm to adopt a process innovation that lowers unit costs. Does it matter whether the firm has extensive market power or operates in a competitive environment? Standard textbook economics (dating from the seminal contribution of Arrow (1962)) says market power matters only to the extent that it affects the output of the firm. The firm should adopt only if the savings in production costs covers the fixed cost of adoption, and for a given level of output this calculation does not depend on market power. Yet there is evidence, and a rapidly growing body of it, that shows firms in more competitive environments are more likely to adopt technologies and increase productivity (see for example Schmitz (2005), Trefler (2002) and the discussion below). And this is true even in situations where changes in market conditions do not have an impact on output. The standard textbook logic is at a loss to explain this evidence.

In this paper, we argue that there is a strong implicit assumption in the textbook story. When we relax this assumption, economic logic now tells us that firms in more competitive environments are more likely to adopt than firms with market power. The textbook model assumes that firms can instantaneously and seamlessly introduce new technologies. In fact, firms often face major problems in integrating new technologies. In some cases, firms have to (temporarily) produce at levels substantially below capacity upon adoption. We call such phenomena switchover disruptions, and present extensive evidence on them below. If firms face switchover disruptions, then they may temporarily lose some unit sales upon adoption. If the firm loses unit sales, then a cost of adoption is the foregone rents on the sales of those units. This is the connection between market power and the incentive to innovate. Greater market power will mean higher prices on those lost units of output, and hence higher lost rents, and those higher lost rents means reduced incentive to innovate.

Having switchover disruptions, then, can change the economic logic as to how increases in market power influence the decision to adopt technology. We illustrate this in two classic models of monopoly and the incentive-to-innovate, the original model of Arrow (1962), and the well known critique by Gilbert and Newbery (1982) (see, for example, Tirole (1988) for a

presentation of these models). We change the adoption technology in both models, from one where costs seamlessly fall upon adoption, to one with switchover disruptions. We show that 
results in both models - results about how changes in market power change the incentive to innovate - can be "overturned" when we use the adoption technology with switchover disruptions rather than "standard" technology. Let us briefly provide some details of our analysis.

Consider a firm in an industry that has an advantage over rivals. We call this the incumbent firm and it initially has a marginal cost of $c^{\circ}$. There are rival firms each having a marginal cost $c^{\circ}+\tau$, for $\tau \geq 0$. The parameter $\tau$ will govern the degree of market power that the incumbent has over its rivals. One interpretation of the parameter is that the incumbent is a domestic firm and the rivals are foreign firms. Foreign firms have the same production cost as the incumbent, but they must incur an additional cost of $\tau$ per unit which could be a tariff or a transportation cost.

There is a new technology with a fixed cost to adopt. If adopted by a firm, its marginal cost begins at $\bar{c}$ and then falls over time to $\underline{c}$, where $\underline{c}<c^{o}$. If costs are immediately lower, that is, $\bar{c}<c^{\circ}$, then this is the standard case considered in the literature. Our generalization is to allow costs to be initially higher, that is, $\bar{c}>c^{\circ}$. There are many reasons why costs may be initially higher and we discuss these below. Such phenomenon are often labeled as glitches, bumps in the road, or kinks in the system. To fix ideas, we'll just say that when $\bar{c}>c^{\circ}$, there is a switchover disruption.

How does the incentive of the incumbent and rivals to adopt the new technology depend on market power in the industry, that is, on $\tau$ ? In order to address this question, we must make more assumptions regarding the environment, such as the strategies available to the firms. There are two classic ways of specifying the environment, and we consider both.

The first approach follows Arrow (1962). Here the incumbent alone has a choice to adopt. The incumbent can pay a fixed cost to adopt the new technology or not. If the incumbent does adopt, the rivals can be excluded and the rivals' costs remain at $c^{\circ}+\tau$. The essence of the Arrow setup is that the incumbent is choosing between having the new technology for itself and no one having it.

The second approach follows Gilbert and Newbery (1982). Here an outsider does research. The outsider sells the fruits of its research to the highest bidder which could be the incumbent or a rival firm. The essence of the Gilbert and Newbery setup is that the incumbent is 
choosing between having the new technology for itself and a rival having it.

Now consider the impact of increasing market power. Consider first the Arrow-environment. With the standard technology for adoption, increasing market power leads to a decrease in the incumbent's incentive to innovate if demand is elastic (sometimes called the replacement effect) due to the reduced output produced when market power expands. If demand is inelastic, increasing market power has no impact on incentives (as we suggested above). However, if there are switchover disruptions, and they are "large" enough (so that the incumbent temporarily loses units sales), then increasing market power decreases the incentive to innovate. In this sense, switchover disruption overturns results in the Arrow model.

Next consider the Gilbert and Newbery-environment. With the standard adoption technology, the incumbent always has a greater willingness to pay than the rival, and the incumbent's willingness to pay increases when market power is increased (sometimes called the efficiency effect). Hence, increases in market power lead to increases in industry innovation. Next, we consider technology adoption with switchover disruption. We show that with "enough" switchover disruption, increases in market power now lead to decreases in industry innovation. For not very large switchover disruption, the incumbent still has a greater willingness to pay than the rival, but the incumbent's willingness to pay decreases when market power is increased. For very large switchover disruption, the rival in fact has a greater willingness to pay (and its willingness is decreasing in market power). As in the Arrow model, then, adding switchover costs overturns results in the Gilbert-Newbery model.

The incentive-to-innovate literature has, obviously, grown significantly in the last 25 years following the Arrow and Gilbert-Newbery debate. Reinganum (1983) made important contributions. It has also extended into more traditional oligopoly models. In fact, there are recent papers that exhaustively look at the incentive-to-innovate literature in these models (see, Vives (2008) and Schmutzler (2007) for a synthesis of this literature). But all this literature, as far as we know, has assumed that firms can instantaneously and seamlessly introduce new technologies. ${ }^{1}$ Switchover disruptions are not considered.

There is an old saying "if you have a good thing going, don't rock the boat." Here, a

\footnotetext{
${ }^{1}$ In some papers there is uncertainty regarding how long it may take to develop an innovation. Similarly, there are models where there is uncertainty as to how much better an innovation will be. But once an innovation is developed, it can be seamlessly adopted.
} 
firm with a lucrative monopoly may decide not to adopt a technology that, in the short-run, disturbs its lucrative position. There is another old saying "if you have nothing to lose, swing for the fences." There are recent papers that have attempted to capture this idea in models where firm's R\&D investment is a choice of variance in outcomes (see, e.g., Anderson and Cabral (2007)). The point is to show that firms that are far behind may decide to choose high variance R\&D programs. Again, switchover disruptions are not considered.

Having switchover disruptions in economic models is by no means new. There is a large literature where switchover disruptions play an important role, for example, in Jovanovic and Nyarko (1996), Chari and Hopenhayn (1991), Klenow (1998), Parente (1994) and Schivardi and Schneider (2008). A major focus of these papers has been to see how switchover disruption influences investment. In that sense, they are close cousins to this paper. However, they have not considered how switchover disruptions in adopting technology might change the relationship between market power and the incentive to innovate.

In Section 2, we provide extensive evidence that firms face switchover disruptions when adopting technology. Section 3 provides the basic model. In Sections 4 and 5, we look at the incentive to innovate in the Arrow and Gilbert-Newbery environments, respectively. Section 6 provides some extensions of the model. In Section 7 we conclude by returning to discuss further evidence on switchover disruptions. Here we discuss evidence on how changes in market power changed the incentives of firms to adopt technology.

\section{Motivating Switchover Disruption}

We use this section to motivate introducing switchover disruptions into the incentive-toinnovate literature. In particular, this section provides evidence that firms often experience such disruptions when they adopt new technologies. In fact, of course, some new technologies never succeed.

One note before we begin. If new technologies can yield higher costs than old ones, firms would obviously run "pilot" projects to learn if new technologies were better or not. Firms obviously do this. But as argued and seen below, for many technologies testing can only reduce uncertainty a modest amount. Pilot projects can often test only one dimension of the 
technology in isolation from others. To know if a technology works can only be learned by turning on all the systems at once. And then the system must be run for substantial periods of time before the productivity of the technology is learned. In this paper, we do not delve into why technology has this feature but explore its consequences. ${ }^{2}$

Let us start by presenting evidence on switchover disruptions faced by three well-known firms. We then turn to more formal studies, looking at switchover costs in manufacturing, supply-chains, and in organizational innovation in general.

\subsection{Switchover Costs in Specific Adoption Episodes}

When discussing evidence, we think its productive to begin with concrete examples of switchover disruptions. We'll give three such cases, though a much larger list is easy to compile. The specific episodes are not meant to be a "test" of our model (i.e., one should not be asking whether the firms have lots of, or little, market power), but simply evidence that disruption is important. A more productive way to test the idea is to look at cases where firms faced large changes in market power, and ask how this changed their adoption decisions. Again, we discuss this in the conclusion.

Boeing. For building the 787 Dreamliner, Boeing chose a new technology, one that involved its suppliers assembling more of the parts off-site than usual, and then shipping to Boeing for final assembly. Such a process had been pursued successfully in other manufacturing industries. However, Boeing has faced major problems - switchover disruptions - in implementing the technology. Suppliers have been slow to send assembled parts, spurring Boeing to request suppliers to ship unassembled work to them. But "Boeing has ended up with a pile of parts and wires, and lots of questions about how they all fit together, not unlike a frustrating Christmas morning at home." With ever growing delays in promised delivery dates, Boeing may lose substantial business to Airbus. Its clear that it is taking Boeing a substantial period of time to learn whether the new system is better than the old. ${ }^{3}$

General Motors. In the 1980s, after suffering large losses in market share to Japanese

\footnotetext{
${ }^{2} \mathrm{~A}$ related issue is why a firm does not immediately switch back to its old technology if costs initially increase with adoption. Again, it is not possible to do so in many (all?) cases as is also seen below.

${ }^{3}$ See coverage in the New York Times, January 16, 2008, "Boeing is Expected to Disclose Further Delays .." and January 17, 2008, "Supplier Woes Lead to New Delay of Boeing 787."
} 
producers, General Motors (GM) invested heavily in automation and robots in order to stem losses in market share. But when factories reopened with their new automation systems, there were major production problems. Robots often did not run. When they did, they "often began dismembering each other, smashing cars, spraying paint everywhere and even fitting the wrong equipment." GM found that "technologies that worked well in isolated pilot projects [weren't] easily coordinated in the real world of high-volume manufacturing." Many of the factories were able to produce only a small share of their rated capacity for months and months. ${ }^{4}$

United Airlines. When a new Denver airport was built in the mid 1990s, United Airlines and the city decided to install a highly automated baggage handling system. There were major switchover disruptions. The system "immediately became known for its ability to mangle and misplace a good portion of everything that wandered into its path." A year after opening, United sued the builder of the system claiming it "performed miserably." For the first decade of operation, United used only a stripped down version of the system. Finally, United decided to turn the system off in $2005 .^{5}$

\subsection{Switchover Costs in Manufacturing}

Steel Manufacturing. Nakamura and Ohashi (2005) examine the experience of Japanese steel manufacturers when they shifted from the open-hearth furnace (OHF) to the basic oxygen furnace (BOF) in the 1950s and 1960s. They found that plants adopting the new technology experienced significant declines in productivity (TFP) at the time of adoption. They estimated a 14\% drop in productivity initially, and that it was three years before the BOF-productivity approached the level of the old OHF-productivity.

General Manufacturing. Some researchers have looked at the productivity experience of manufacturing plants after they have undergone a major surge in investment. Using

\footnotetext{
${ }^{4}$ For coverage see "When GM's Robots Ran Amok," The Economist, 8/10/91, Vol. 320, Issue 7719, "Tricky Auto Makers Discover 'Factory of the Future' is Headache Just Now," The Wall Street Journal, May 13, 1986, "Detroit Stumbles on Its Way to the Future," BusinessWeek, June 16, 1986.

${ }^{5}$ United's lease (in 2002) requires it to pay the city $\$ 60$ million a year for the automated system (for 25 years). Hence, United must swallow this loss. However, United will reduce its operating costs by returning to manual baggage handling, and expects to save $\$ 12$ million a year on these costs.For coverage of this story, see "United Abandons Denver Baggage System," Associated Press, June 7, 2005, and "Denver Airport Saw the Future. It Didn't Work," New York Times, August 27, 2005.
} 
these surges as proxies for adoption of technology, they have found that productivity has initially fallen after adoption. Studies include Huggett and Ospina (2001) who looked at what happened to trend productivity growth after adoption, and Sakellaris (2004) who looked at the impact on levels of productivity.

\subsection{Switchover Costs in Supply-Chain Management}

Changes in supply-chain systems will almost certainly cause switchover disruptions. There is no way of knowing if a system is better without trying it. Boeing is now in the process of such learning. There is a thriving literature in operations research and management that has studied the consequences of supply chain disruptions, brought on by glitches in moving to new technology and other sources of disruption. The literature has found large losses in productivity and share value as a result of glitches (see, e.g., Hendricks and Singhal (2003, 2005) and references therein).

\subsection{Switchover Costs in Organizational Changes}

Organizational changes will almost certainly cause switchover disruptions. A new organizational structure might be better or worse, but there is really no way of knowing without the entire organization trying it. If it is worse, there is no way to switch back to the old organization overnight if at all. We'll discuss a few areas in which firms attempt to improve their organizations (and lower their production costs).

Work Rule Changes. A subset of organizational innovation involves firms changing work

rules of a union. Here it may be clear that a new set of work rules (more flexible ones) would lead to much lower costs. Yet introducing the changes might lead to a union strike and a considerable period of downtime. Indeed there are many episodes where firms were shut down for long periods before being able to change the work rules, and in some instances, were not able to change them at all.

A Potpourri of Workplace Changes. To finish our motivation of adding switchover disruption, lets list a few departments in organizations, and papers describing switchover disruptions upon innovation in these departments. Marketing departments have faced disrup- 
tions introducing sales force automation technology (see, e.g., Speier and Venkatesh (2002)).

Human resource departments have faced disruptions in introducing new workplace compensation schemes (see, e.g., Beer and Cannon (2004)). And, of course, introducing new information technology systems often leads to significant disruptions (see, e.g., Ginzberg (1981)).

\section{Model}

Consider an industry with demand function $D(p)$. We will distinguish between the downwardsloping demand case where $D^{\prime}(p)<0$ and the inelastic case where there is a reservation price $\theta$ for a unit demand, that is, $D(p)=1$, for $p \leq \theta$ and $D(p)=0$ for $p>\theta$.

There is a firm in the industry that has an advantage over rivals. We call this the incumbent and it initially has a marginal cost of $c^{\circ}$. There are a set of (more than one) rival firms each having a marginal cost equal to $c^{\circ}+\tau$, for $\tau \geq 0$. The parameter $\tau$ will govern the degree of market power that the incumbent has over its rivals. One interpretation of the parameter is that the incumbent is a domestic firm and the rivals are foreign firms. All firms have the same production cost $c^{\circ}$, but the foreign firms must incur an additional cost of $\tau$ per unit which could be a tariff or a transportation cost. The parameter $\tau$ will be the key element in our comparative statics.

Define the pure monopoly price at the initial marginal cost of $c^{\circ}$ to be

$$
p_{0}^{M}=\arg \max _{p}\left(p-c^{\circ}\right) D(p)
$$

Assume that $p_{0}^{M} \geq c^{\circ}+\tau{ }^{6}$ Suppose that the firms compete in a Bertrand fashion. Thus, if the incumbent's cost remains at the initial level $c^{\circ}$ and the rivals' at $c^{\circ}+\tau$, the equilibrium price from Bertrand competition is the limit price $p_{0}=c^{\circ}+\tau$ and all sales go to the incumbent.

There exists a new technology. To explain the new technology, we introduce a time dimension in the model. Production takes place over a unit time interval $t \in[0,1]$. If it were

\footnotetext{
${ }^{6}$ Make the further technical assumption that for any cost $c$, monopoly profit $(p-c) D(p)$ is single-peaked in price.
} 
not for the new technology, introducing the time element would add nothing, as demand and cost would be constant over time and the analysis could go through as though it were just a static problem. The dynamics play a role when the new technology is adopted because in this case cost varies over time.

Specifically, assume that if the new technology is adopted at time $t=0$, then marginal cost at time $t$ equals $c_{t}=f(t)$ where $f(\cdot)$ is a continuous strictly decreasing function, $f^{\prime}(t)<0$. Let $\bar{c}=f(0)$ be the high initial cost and $\underline{c}=f(1)$ be the low cost ultimately attained, $\underline{c}<\bar{c}$.

It will be convenient in the analysis to integrate over the cost path $c(t)$ rather than over $t$. For for $c \in[\underline{c}, \bar{c}]$, let $G(c)$ denote how much time remains when marginal cost equals $c$. That is, $G(c)$ is the value of $x$ solving $f(1-x)=c$. Thus $G(\bar{c})=1$ and $G(\underline{c})=0$, and $0<G(c)<1$ for $\underline{c}<c<\bar{c}$. The c.d.f. over marginal cost during the time interval is $1-G(\cdot)$ and let $g(c)=-G^{\prime}(c)$ be the density of marginal cost. Finally, letting $\rho$ be the discount rate, define $h(c)$ as

$$
h(c) \equiv e^{-\rho(1-G(c))} g(c) .
$$

This will show up in the formulas below as the weight on profits when cost is $c$. The first term takes into account discounting, since the time is $t=1-G(c)$ when cost is $c$. The second term takes into account the density of $c$.

We assume that $\underline{c}<c^{\circ}$ so that ultimately the new technology is better than the original. The key innovation in our analysis is to allow for the possibility that $\bar{c}>c^{\circ}$. When that happens we say there is a switchover disruption at the initial point of adoption. Figure 1 illustrates an example. We can think of there being some prior period $t \in[-1,0)$ over which cost was constant at $c^{\circ}$. When the new technology is adopted, marginal cost goes up initially, but eventually is lower.

The next issue is: Who gets to adopt the new technology? There are two classic ways of setting this up in the literature and we consider both. The first approach follows Arrow (1962). Here the incumbent alone has a choice to adopt. The incumbent can pay a fixed cost to adopt the new technology or pay no fixed cost and use the original technology instead. If the incumbent does adopt, the rivals can be excluded and the rivals' fixed cost remains at $c^{\circ}+\tau$. The essence of the Arrow setup is that the incumbent is choosing between having 
the new technology for itself and no one having it.

The second approach follows Gilbert and Newbery (1982). Here an outsider is doing research. The outsider can sell the fruits of its research to the highest bidder which could potentially be the incumbent firm or a rival firm. The essence of the Gilbert and Newbery setup is that the incumbent is choosing between having the new technology for itself and a rival having it.

\section{Monopoly and the Incentive to Innovate: Arrow}

In this section we take the Arrow setup and work through the comparative statics of how the incentive to innovate depends upon the monopoly power parameter $\tau$.

We begin our analysis by first configuring our model so that it is equivalent to the standard setup and then rederiving the standard result. We do this by initially supposing that $\bar{c} \leq c^{\circ}$ meaning there is no switchover disruption. Costs fall right away upon adoption and improve after that. We examine the incentive of the incumbent to innovate in this situation.

As explained earlier, if the incumbent does not innovate, the equilibrium price from Bertrand competition will be $p^{\circ}=c^{\circ}+\tau$ yielding a profit margin of $\tau=p^{\circ}-c^{\circ}$ per unit sold. The incumbent's sales will be $Q^{\circ}=D\left(c^{\circ}+\tau\right)$ at each instant along the unit time interval.

If the incumbent adopts, it obtains a cost path that starts with $\bar{c}$ and decreases to $\underline{c}$ over the unit interval. Following the terminology in the literature, assume that $\underline{c}$ is not a drastic cost reduction relative to $c^{\circ}$ so that the monopoly price at $\operatorname{cost} \underline{c}$ remains above $c^{\circ}+\tau$. Thus if the incumbent adopts, it continues to set the limit price $p_{0}=c^{\circ}+\tau$ at each time instant, so quantity sold by the incumbent is the same whether or not it innovates. Therefore, for the no switchover disruptions case, the present value to the incumbent from adoption is

$$
v^{N o_{-} S D}=D\left(c^{\circ}+\tau\right) \int_{\underline{c}}^{\bar{c}} h(c)\left[c^{\circ}+\tau-c\right] d c
$$

where "No_SD" denotes no switchover disruption. Note it is convenient to integrate over cost rather than time and we are using the weight $h(c)$ defined in (1) that takes into account discounting and the density of $c$. 
Analogously, the present value of not adopting is $\left(p^{\circ}-c^{\circ}\right) D\left(c^{\circ}+\tau\right)$. Subtracting this from $v^{N o_{-} S D}$, the net gain from adopting rather than not adopting is

$$
W_{\text {Arrow }}^{\text {No_SD }}=\left[\int_{\underline{c}}^{\bar{c}} h(c)\left(c^{\circ}-c\right) d c\right] D\left(c^{\circ}+\tau\right)
$$

This is the present value of the savings in variable cost from the new technology. Now suppose there is some fixed cost $F$ of adoption. It is immediate that the incumbent adopts if the value of adoption $W$ exceeds the cost $F$.

We are interested in comparative statics with $\tau$. If we think of the fixed $\operatorname{cost} F$ as having been drawn from some continuous distribution, then if $W_{\text {Arrow }}^{\text {No_SD }}$ decreases in $\tau$, the incumbent is less likely to adopt with more market power $\tau$.

In the downward sloping demand case where $D^{\prime}(p)<0$, it is immediate from (3) that $W_{\text {Arrow }}^{\text {No } S D}$ is strictly decreasing in the degree of market power $\tau$. This is a version of a well-known result due to Arrow that is called the replacement effect. The economics is straightforward. Adoption of the new technology involves the payment of a fixed cost to lower marginal cost. The greater the monopoly power $\tau$, the lower the production volume $D\left(c^{\circ}+\tau\right)$ over which to spread the fixed cost of innovation and therefore the less the incentive to pay this fixed cost.

Hereafter we focus on the inelastic demand case where $D\left(c^{\circ}+\tau\right)$ is constant at unity. With the standard adoption technology, that is, $\bar{c} \leq c^{\circ}$, so there is no switchover disruption, it is immediate that the willingness to pay for an innovation in (3) is constant in $\tau$. In other words, in the inelastic demand case, increasing market power does not change the incentives to adopt.

Now assume there is switchover disruption, meaning $\bar{c}>c^{\circ}$. For very small switchover disruption $-\bar{c}$ very close to $c^{\circ}$ - the results above will apply. So, we focus on the case where the switchover disruption is "big" relative to market power, in particular, we consider comparative statics from changing $\tau$ in the range $\tau \in\left(0, \bar{c}-c^{\circ}\right)$. For such $\tau$ and $\bar{c}$, there is an initial time interval over which the incumbent is no longer the low cost producer. The incumbent must wait until its cost falls to $c^{\circ}+\tau$ before it again becomes the low-cost producer. 
In this case, the return from adopting is

$$
v^{S D}=\int_{\underline{c}}^{c^{\circ}+\tau} h(c)\left[c^{\circ}+\tau-c\right] d c
$$

where " $S D$ " denotes switchover disruption. The willingness to pay for the innovation is the difference between $v^{S D}$ and the return from not adopting, or

$$
W_{\text {Arrow }}^{S D}=\int_{\underline{c}}^{c^{\circ}+\tau} h(c)\left[c^{\circ}+\tau-c\right] d c-\int_{\underline{c}}^{\bar{c}} h(c) \tau d c
$$

where recall $D\left(c^{\circ}+\tau\right)$ is unity. Note that if the incumbent adopts, it only enjoys profits for $c$ in the range $\left[\underline{c}, c^{\circ}+\tau\right]$. In contrast, if it had not adopted, it would have enjoyed a profit of $\tau$ over the entire interval. Differentiating with respect to the market power parameter $\tau$ we get

$$
\frac{d W_{\text {Arrow }}^{S D}}{d \tau}=-\int_{c^{\circ}+\tau}^{\bar{c}} h(c) d c<0, \text { for } \tau<\left(\bar{c}-c^{\circ}\right) .
$$

Now if $\tau$ is greater than $\left(\bar{c}-c^{\circ}\right)$, then the incumbent adopting the new technology holds onto the market even initially. And so the effect of a change in $\tau$ is zero. The effect we are talking about comes into play when the increase in marginal cost at the point of switchover is big enough relative to the monopoly friction that the incumbent is initially not the low cost producer.

These last results are illustrated in Figure 2. In that figure, there are two identical panels, except that the switchover disruption in the left hand panel is "small" (that is, $c^{\circ}+\tau>\bar{c}$ ) and is "large" in the right hand panel. Assume that there is no discounting. Then the dark shaded area in both panels represents the total profits that are lost as a result of the disruption, and the light shaded area are the profits that are gained when costs fall below original costs. In the left hand panel, increases in $\tau$ do not change either shaded area. In the right hand panel, increases in $\tau$ increase the size of the dark shaded area, and hence makes innovation less likely.

We summarize the results of this section with

Proposition 1. Assume the Arrow setup applies. (i) Suppose demand is elastic. If there is no switchover disruption $\left(\bar{c} \leq c^{\circ}\right)$, then $W_{\text {Arrow }}^{\text {No_ } S D}$ strictly decreases in the monopoly parameter $\tau$. 
(ii) Suppose demand is inelastic. If there is no switchover disruption $\left(\bar{c} \leq c^{\circ}\right)$, then $W_{A r r o w}^{N o \_} S D$ is constant in $\tau$. Suppose there is a switchover disruption $\left(\bar{c}>c^{\circ}\right)$. Then $W_{\text {Arrow }}^{S D}$ strictly decreases in $\tau$ for $\tau \in\left(0, \bar{c}-c^{\circ}\right)$.

An important point before moving on. In the case of a large switchover disruption, the monopolist loses its entire market for a period of time. This, of course, is simply an artifact of the simple model above. The monopolist does not have to lose its entire market in order for the effect we are talking about to be important. There are other ways to set up the model, and in which Proposition 1 still obtains, in which the incumbent loses only a part of its market when it adopts the technology. For example, the incumbent could face its rivals in many markets (and not just one) and have a large cost advantage (i.e., large $\tau$ ) in some, and a small cost advantage in others. Upon adoption, it will be a low cost producer in some markets, but not others. Below we present an such an extension of the model.

\section{Monopoly and the Incentive to Innovate: Gilbert and Newbery}

We begin with details of the environment. An outside researcher has an opportunity to engage in research to develop the new technology. If it innovates, it can sell exclusive rights to use the technology to the incumbent or one of the rivals. If a rival uses the new technology, it still needs to pay the friction $\tau$, in addition to the marginal production cost. Assume that the outside researcher can commit to an auction technology that extracts the full surplus from the bidder with the highest willingness to pay. Let $W_{G N}^{N O_{-} S D}$ and $W_{G N}^{S D}$ be defined as the willingness to pay of the highest bidder in the case there is not a switchover disruption and there is a switchover disruption respectively. The object of this section is to determine how willingness to pay varies with $\tau$. Furthermore, we will be interested in determining the identity of the highest bidder, the incumbent or a rival? To abstract away from the replacement-effect type issues, we focus on the case of perfectly inelastic demand.

We begin with some additional notation. As in the previous section, let $v$ denote the present value to the incumbent when it acquires the new technology. Now let $u$ denote the 
present value to the incumbent when a rival obtains the new technology. Finally, let $r$ be the present value to a rival when it acquires the new technology.

\subsection{Adoption with no switchover disruption}

We begin with the case of no switchover disruption, $\bar{c} \leq c^{\circ}$. The value $v^{N o}{ }_{-} D$ to the incumbent of acquiring the rights to the new technology is the same as formula (2) in the previous subsection (with $D\left(c^{\circ}+\tau\right)$ at unity). Note that here we don't need to worry that the incumbent will buy the technology and leave it idle, as this is never optimal without a switchover disruption. (We will have to worry about this possibility when we examine switchover disruptions.) The value $u^{N o \_} S D$ to the incumbent if the rights are acquired by a rival firm is

$$
u^{N o_{-} S D}=\int_{\max \left\{c^{\circ}-\tau, \underline{c}\right\}}^{\max \left\{\bar{c}, c^{\circ}-\tau\right\}} h(c)\left[c+\tau-c^{\circ}\right] d c .
$$

By using the max operator in (7) above, we subsume different cases. If $\max \left\{\bar{c}, c^{\circ}-\tau\right\}=$ $c^{\circ}-\tau$ (equivalently $c^{\circ} \geq \bar{c}+\tau$ ), the incumbent is immediately undercut at the point of adoption by a rival and the integral above is 0 (limits of integration are $c^{\circ}-\tau$ and $c^{\circ}-\tau$ ). If alternatively $c^{\circ}<\bar{c}+\tau$, the incumbent is at least initially the low cost producer, taking into account the friction $\tau$, but it will have to set the price to $c+\tau$ to match the adopting rival.

Finally, the value to a rival if the rival acquires the new technology rights is

$$
r^{N o_{-} S D}=\int_{\min \left\{\underline{c}, c^{\circ}-\tau\right\}}^{\min \left\{\bar{c}, c^{\circ}-\tau\right\}} h(c)\left[c^{\circ}-\tau-c\right] d c,
$$

where, again, by using the min operator above we subsume different cases.

The maximum willingness to pay for the rights to the new innovation is

$$
\begin{aligned}
W_{G N}^{N o \_} S D & =\max \left\{v^{N o \_S D}-u^{N o \_S D}, r^{N o \_} S D\right\} \\
& =\max \left\{\begin{array}{c}
\int_{\underline{c}}^{\bar{c}} h(c)\left[c^{\circ}+\tau-c\right] d c-\int_{\max \left\{c^{\circ}-\tau, \underline{c}\right\}}^{\max \{\bar{\circ}-\tau\}} h(c)\left[c+\tau-c^{\circ}\right] d c, \\
\int_{\min \left\{\underline{c}, c^{\circ}-\tau\right\}}^{\min \left\{\bar{c}, c^{\circ}-\tau\right\}} h(c)\left[c^{\circ}-\tau-c\right] d c
\end{array}\right\} .
\end{aligned}
$$


The first term in the maximization is the willingness to pay by the incumbent, the difference in return between having the production rights and a rival having them. The second term is the return to a rival owning the rights (a rival without rights gets profit equal to zero.)

Observe that at $\tau=0$, the willingness to pay by the incumbent and a rival is the same and equal to

$$
W_{G N}^{N o-S D}=\int_{\underline{c}}^{\bar{c}} h(c)\left[c^{\circ}-c\right] d c, \text { when } \tau=0,
$$

the present value of the cost reduction. This expression follows from the fact that, with no switchover disruption, $\max \left\{\bar{c}, c^{\circ}-\tau\right\}=\max \left\{c^{\circ}-\tau, \underline{c}\right\}=c^{\circ}$ (when $\tau=0$ ), and $\min \left\{\bar{c}, c^{\circ}-\tau\right\}=$ $\bar{c}$ and $\min \left\{\underline{c}, c^{\circ}-\tau\right\}=\underline{c}$. Next observe that the willingness to pay $r^{N o \_} S D$ of the rival strictly decreases in $\tau$. Finally, we differentiate $v^{N o_{-} S D}-u^{N o_{-} S D}$. Lets first note that

$$
\frac{d v^{N o \_} S D}{d \tau}=\int_{\underline{c}}^{\bar{c}} h(c) d c .
$$

The derivative $d u^{N o \_} S D / d \tau$ is the sum of the following three terms,

$$
-\frac{d \max \left\{c^{\circ}-\tau, \underline{c}\right\}}{d \tau} h\left(\max \left\{c^{\circ}-\tau, \underline{c}\right\}\right)\left[\max \left\{c^{\circ}-\tau, \underline{c}\right\}+\tau-c^{\circ}\right],
$$

and

$$
\frac{d \max \left\{\bar{c}, c^{\circ}-\tau\right\}}{d \tau} h\left(\max \left\{\bar{c}, c^{\circ}-\tau\right\}\right)\left[\max \left\{\bar{c}, c^{\circ}-\tau\right\}+\tau-c^{\circ}\right],
$$

and finally

$$
\int_{\max \left\{c^{\circ}-\tau, c\right\}}^{\max \left\{\bar{c}, c^{\circ}-\tau\right\}} h(c) d c .
$$

The first two terms are zero (in each term, either the derivatives are zero, or if not, the rest of the expression is zero). Hence,

$$
\frac{d u^{N o \_} S D}{d \tau}=\int_{\max \left\{c^{\circ}-\tau, \underline{c}\right\}}^{\max \left\{\bar{c}, c^{\circ}-\tau\right\}} h(c) d c
$$

and hence

$$
\frac{d v^{N o \_S D}}{d \tau}-\frac{d u^{N o \_S D}}{d \tau}=\int_{\underline{c}}^{\bar{c}} h(c) d c-\int_{\max \left\{c^{\circ}-\tau, c\right\}}^{\max \left\{\bar{c}, c^{\circ}-\tau\right\}} h(c) d c .
$$


This last derivative is strictly positive if $\tau<c^{\circ}-\underline{c}$ and zero for $\tau \geq c^{\circ}-\underline{c}$. Hence for $\tau>0$, the willingness to pay by the incumbent strictly exceeds that of the rival, and the willingness strictly increases in $\tau$ up to the threshold. In summary, we have proved:

Proposition 2. Assume the Gilbert and Newbery setup applies, that demand is perfectly inelastic, and that there is no switchover disruption $\left(\bar{c} \leq c^{\circ}\right)$.

(i) If $\tau>0$, the incumbent has a higher willingness to pay for the new innovation and so will outbid the rival so $W_{G N}^{N o \_}{ }^{N D}=v^{N o \_} S D-u^{N o \_} S D$.

(ii) $W_{G N}^{N o-} S D$ strictly increases in $\tau$ for $\tau<c^{\circ}-\underline{c}$ and is constant above this point.

Part (i) of the proposition is a variant of Gilbert and Newbery's famous result that innovation is worth more to the incumbent than a new entrant and so the incumbent will preemptively patent before a rival. The incumbent will take into account that if it does not preemptively innovate and the entrant adopts instead, the incumbent will lose its monopoly rent. In contrast, the rivals have no rent to forego if they don't innovate.

Part (ii) of the result is really an elaboration on part (i). The larger is $\tau$ the larger is the incentive of the incumbent to hold onto its monopoly rents and so the more the incumbent is willing pay for the innovation. This remains true until $\tau>c^{\circ}-\underline{c}$. When the friction is bigger than this threshold, a rival cannot displace the incumbent even when its costs have fallen to $\underline{c}$. So the incumbent will enjoy the full value of the friction $\tau$ whether or not the incumbent or a rival have the new technology, meaning changes in $\tau$ don't impact willingness to pay.

\subsection{Adoption with switchover disruption}

The intuition embodied in Proposition 2 for how monopoly can raise the incentive to pay for innovation is well understood. The key point we want to make here is that this result depends heavily on the assumption that there are no switchover disruptions. We will show that the presence of switchover disruptions can overturn the results in Proposition 2. Note that we must now allow the possibility that the incumbent buys the technology and leaves it idle. 
The statement of our result will require two additional pieces of notation. Let

$$
\begin{aligned}
H^{\text {disrupt }} & \equiv \int_{c^{\circ}}^{\bar{c}} h(c) d c \\
H^{\text {beyond }} & \equiv \int_{\underline{c}}^{c^{\circ}} h(c) d c .
\end{aligned}
$$

Here $H^{\text {disrupt }}$ is the (weighted) duration of the switchover disruption, where the weight depends upon the cost density and the discount factor, and $H^{\text {beyond }}$ is the (weighted) duration "beyond the disruption," when cost is lower than its initial value $c^{\circ}$.

We start by determining what happens when the degree of market power $\tau$ is small. Proposition 3. Assume the Gilbert and Newbery setup applies, that demand is perfectly inelastic, and that there is a period of switchover disruption $\left(\bar{c}>c^{\circ}\right)$. Suppose that $\tau$ is small.

(i) If $H^{\text {disrupt }}<H^{\text {beyond }}$, then the incumbent obtains the innovation and $W_{G N}^{S D}$ strictly increases in $\tau$.

(ii) If $H^{\text {disrupt }} \in\left(H^{\text {beyond }}, 2 H^{\text {beyond }}\right)$, then the incumbent still obtains the innovation, but $W_{G N}^{S D}$ strictly decreases in $\tau$.

(iii) If $H^{\text {disrupt }}>2 H^{\text {beyond }}$, then a rival obtains the innovation and $W_{G N}^{S D}$ strictly decreases in $\tau$.

Proof. Suppose $\bar{c}>c^{\circ}$ and $\tau \in\left(0, c^{\circ}-\underline{c}\right)$. To do the analysis, we need to derive four different returns.

First Return: $v^{S D}$

This is the return to the incumbent from adopting the technology,

$$
v^{S D}=\int_{\underline{c}}^{\min \left\{c^{\circ}+\tau, \bar{c}\right\}} h(c)\left[c^{\circ}+\tau-c\right] d c
$$

where if $\min \left\{c^{\circ}+\tau, \bar{c}\right\}=\bar{c}$, the incumbent is always the low cost producer.

Second Return: $i^{S D}$

This is the return if the incumbent acquires the rights to the new technology but leaves it idle. Hence no rival adopts. We ignored this possibility in the non-disruption case because 
it was irrelevant there. But it can be relevant here. The return is

$$
i^{S D}=\int_{\underline{c}}^{\bar{c}} h(c) \tau d c
$$

since the markup is $\tau$, and demand is unity.

Third Return: $u^{S D}$

This is the return to the incumbent of not acquiring the technology (so that it ends up in the hands of a rival),

$$
u^{S D}=\int_{c^{\circ}}^{\bar{c}} h(c) \tau d c+\int_{c^{\circ}-\tau}^{c^{\circ}} h(c)\left[c+\tau-c^{\circ}\right] d c .
$$

The first term is the return over the disruption interval, that is, the time before the adopting rival's cost (not including the friction $\tau$ ) has fallen to $c^{\circ}$, that is, the interval $\left[c^{\circ}, \bar{c}\right]$. The adopting rival begins with total cost $\bar{c}+\tau$ (which satisfies $\bar{c}+\tau>c^{\circ}+\tau>c^{\circ}$ ), but since there are other rivals (we assumed multiple rivals) with cost $c^{\circ}+\tau$, the incumbent's limit price is $c^{\circ}+\tau$, and its markup $\tau$. The second term is the return after the disruption interval. In this period, the adopting rival has a cost $c+\tau<c^{\circ}+\tau$. For the first part of this period, the incumbent's cost $c^{\circ}$ remains lower then $c+\tau$, during which period the equilibrium price is $c+\tau$. Eventually, since $\underline{c}<c^{\circ}$ and since $\tau<c^{\circ}-\underline{c}$ by assumption (since $\tau$ is assumed "small"), a point is reached (i.e., $c+\tau=c^{\circ}$ ) where the rival that adopts is the lowest cost producer (including the friction $\tau$ ) and the incumbent's profit is zero from that point on. Fourth Return: $r^{S D}$

The return to a rival of adopting the technology is

$$
r^{S D}=\int_{\underline{c}}^{c^{\circ}-\tau} h(c)\left[c^{\circ}-\tau-c\right] d c
$$

since its limit price is $c^{\circ}$, and its marginal cost is $c+\tau$.

Willingness to pay in the switchover disruption case is given by

$$
W_{G N}^{S D}=\max \left\{v^{S D}-u^{S D}, i^{S D}-u^{S D}, r^{S D}\right\}
$$


We begin by noting that for $\tau$ close to zero, it is immediate that $v^{S D}>i^{S D}$, so we can ignore the idling possibility for the rest of this proof. So we compare $v^{S D}-u^{S D}$ and $r^{S D}$. Note at $\tau=0$ they are equal. Let us differentiate the difference, $v^{S D}-u^{S D}$, with respect to $\tau$. First, we have that

$$
\frac{d v^{S D}}{d \tau}=\frac{d \min \left\{c^{\circ}+\tau, \bar{c}\right\}}{d \tau} h\left(\min \left\{c^{\circ}+\tau, \bar{c}\right\}\right)\left[c^{\circ}+\tau-\min \left\{c^{\circ}+\tau, \bar{c}\right\}\right]+\int_{\underline{c}}^{\min \left\{c^{\circ}+\tau, \bar{c}\right\}} h(c) d c,
$$

where note that the first term is zero. Hence, we have that

$$
\frac{d v^{S D}}{d \tau}-\frac{d u^{S D}}{d \tau}=\int_{\underline{c}}^{\min \left\{c^{\circ}+\tau, \bar{c}\right\}} h(c) d c-\int_{c^{\circ}-\tau}^{\bar{c}} h(c) d c
$$

and note that, at $\tau=0, d v^{S D} / d \tau-d u^{S D} / d \tau=H^{\text {beyond }}-H^{\text {disrupt }}$. Next, we have

$$
\frac{d r^{S D}}{d \tau}=-\int_{\underline{c}}^{c^{\circ}-\tau} h(c) d c
$$

and note that, at $\tau=0, d r^{S D} / d \tau=-H^{\text {beyond }}$.

If $H^{\text {beyond }}>H^{\text {disrupt }}$, then for $\tau=0,(10)$ is positive and greater than (11). This implies that the incumbent has the highest willingness to pay for small $\tau$. Thus $W_{G N}^{S D}=v^{S D}-u^{S D}$, and this is strictly increasing for small $\tau$, proving (i).

If $H^{\text {disrupt }} \in\left(H^{\text {beyond }}, 2 H^{\text {beyond }}\right)$, then $(10)$ is strictly negative but still greater than (11). Thus $W_{G N}^{S D}=v^{S D}-u^{S D}$ and is strictly decreasing for small $\tau$, proving (ii).

If $H^{\text {disrupt }}>2 H^{\text {beyond }}$, then (10) is strictly less than (11). So a rival has the highest willingness to pay. So $W_{G N}^{S D}=r^{S D}$ which is strictly decreasing, proving (iii). Q.E.D.

The above is a local result, holding around $\tau=0$. The next result (Proposition 4) generalizes the two ways that big switchover costs overturn GN (which are parts (ii) and (iii) of Proposition 3) to a wider range of $\tau$. Before stating Proposition 4, we need to deal with the complication that for certain parameters, it may be the case that the incumbent obtains the rights to the innovation but then leaves it idle. The following lemma shows that if this ever happens for any $\tau$, it happens for all higher $\tau$.

Lemma 1. Fix all the parameters of the model except for $\tau$. If there exists any $\tau$ where the 
incumbent obtains the new innovation rights but then idles it (and has a strict preference to do so), there is a $\hat{\tau}>0$ such that for all $\tau<\hat{\tau}$, the incumbent does not obtain and idle the new innovation but if $\tau>\hat{\tau}$ the incumbent does obtain the rights and idles it.

Proof. See appendix.

Define $\hat{\tau}=\infty$ in the event that there is no idling for any $\tau$. Proposition 4 requires an additional assumption.

Assumption 1: Assume that $f^{\prime}(t) e^{\rho t}$ increases in $t$.

A few remarks about assumption 1. We earlier assumed that $f^{\prime}(t)<0$. Now if the discount rate were $\rho=0$, this assumption would be simply be that $f^{\prime \prime}>0$, i.e. that $f$ is convex such as in the example in figure 1. This would be a standard assumption in any kind of learning over time setup where the initial advances come in at a faster rate than later advances. If $\rho>0$, we need more than convexity since the $e^{\rho t}$ term works against the assumption (note $f^{\prime}(t)<0$ ). We need $f$ to be convex enough. For example, if $f(t)=k e^{-\gamma t}$, then we need $\gamma>\rho$ for the assumption to hold. Assumption 1 directly implies that $h(c)$ decreases in $c .^{7}$

With this setup, we can now generalize the two ways that big switchover costs overturn GN (which are parts (ii) and (iii) of Proposition 3) to a wider range of $\tau$.

Proposition 4. As in Proposition 3, assume the Gilbert and Newbery setup applies, that demand is perfectly inelastic and that there is a period of switchover disturbance $\left(\bar{c}>c^{\circ}\right)$. Assume further that Assumption 1 holds.

(i) If $H^{\text {disrupt }}>H^{\text {beyond }}, W_{G N}^{S D}$ strictly decreases in $\tau$ for $\tau<\min \left\{c^{\circ}-\underline{c}, \hat{\tau}\right\}$.

(ii) If $H^{\text {disrupt }}>2 H^{\text {beyond }}$, a rival obtains the innovation for all $\tau<\min \left\{c^{\circ}-\underline{c}, \hat{\tau}\right\}$.

Proof. For $\tau<\min \left\{c^{\circ}-\underline{c}, \hat{\tau}\right\}$, by the definition of $\hat{\tau}$, the incumbent is not idling the technology. Hence, the formula (10) is valid for $\tau$ in this range. Differentiating again yields

$$
\begin{aligned}
\frac{d^{2} v^{S D}}{d \tau^{2}}-\frac{d^{2} u^{S D}}{d \tau^{2}} & =h\left(c^{\circ}+\tau\right)-h\left(c^{\circ}-\tau\right), \text { if } c^{\circ}+\tau<\bar{c}, \\
& =-h\left(c^{\circ}-\tau\right), \text { if } c^{\circ}+\tau>\bar{c}
\end{aligned}
$$

Assumption 1 implies $h^{\prime}<0$, so the above is strictly negative. Since $H^{\text {disrupt }}>H^{\text {beyond }}$,

\footnotetext{
${ }^{7}$ Recall that $h(c) \equiv e^{-\rho(1-G(c))} g(c)=-e^{-\rho t} f(t)^{-1}$, for $t$ solving $c=f(t)$.
} 
$v^{S D}-u^{S D}$ is strictly decreasing for small $\tau$. Since the function is strictly concave, it is then strictly decreasing for all $\tau \in\left(0, c^{\circ}-\underline{c}\right)$. Next note from (11) that $r^{S D}$ is strictly decreasing. Now $W_{G N}^{S D} \equiv \max \left\{v^{S D}-u^{S D}, r^{S D}\right\}$ where $v^{S D}-u^{S D}$ and $r^{S D}$ are both decreasing functions of $\tau$. The maximum of decreasing functions is a decreasing function, proving (i). Next observe from differentiating (11) with respect to $\tau$ that $r^{S D}$ is (weakly) convex. If $H^{\text {disrupt }}>2 H^{\text {beyond }}$, the slope of $r^{S D}$ at $\tau=0$ is strictly greater than the slope of $v^{S D}-u^{S D}$. Since $r^{S D}$ is convex and $v^{S D}-u^{S D}$ is concave and since $v^{S D}-u^{S D}=r^{S D}$ at $\tau=0, r^{S D}>v^{S D}-u^{S D}$ for $\tau \in\left(0, \min \left\{c^{\circ}-\underline{c}, \hat{\tau}\right\}\right)$ as claimed. Q.E.D.

The intuition of the results for the Gilbert and Newbery structure can be gleaned from a simple example. Ignore discounting by setting $\rho=0$. Suppose that during the disruption period, marginal cost is infinite, that is, $\bar{c}=\infty$, so that no production can take place. Once the disruption period is over, then marginal cost is $\underline{c}<\left(c^{\circ}-\tau\right)$. If the incumbent adopts the technology, it enjoys a profit only after the disruption interval has passed. Hence,

$$
v^{S D}=H^{\text {beyond }}\left(c^{\circ}+\tau-\underline{c}\right) .
$$

If the incumbent doesn't adopt so that the rival gets it, it makes a profit only as long as the adopting rival is still in the disruption phase, that is,

$$
u^{S D}=H^{\text {disrupt }} \tau .
$$

The willingness of the incumbent to pay for the innovation is

$$
W_{G N}^{S D}=v^{S D}-u^{S D}=H^{\text {beyond }}\left(c^{\circ}+\tau-\underline{c}\right)-H^{\text {disrupt }} \tau .
$$

We can easily see here that if the $H^{\text {disrupt }}$ period is longer than the $H^{\text {beyond }}$ period, an increase in $\tau$ will lower the incumbents willingness to pay for the innovation. Obviously, the disruption period has to be quite big here, half of the entire period. But note that if we add discounting, the disruption period need not be so long for the result to go through since 
the disruption is bourne up front. So adding discounting magnifies the effect. ${ }^{8}$ Below we illustrate another force that magnifies the effect.

\section{Extensions}

In this section, we show our conclusions are robust to some straightforward extensions and alternative interpretations.

Incumbent faces rivals in many markets (i.e. variation in $\tau$ )

In the case of a large switchover disruption, in the analysis above the incumbent loses its entire market for a period of time. But in more general models, the incumbent need not lose its entire market in order for the effect we are talking about to go through. ${ }^{9}$ We illustrate this here by allowing the incumbent's advantage over rivals to be big in some markets, and small in others. In this setup, even during the switchover disruption when the incumbent has high costs it will nonetheless continue to sell to consumers over whom it has high monopoly power. The incumbent will lose mobile consumers during the disruption and on account of these mobile consumers our results will go through.

So now assume that there is heterogeneity in $\tau$ in the population of consumers rather than all consumers having the same $\tau$. Specifically, assume $\tau$ is distributed on the interval $\tau \in[0, \bar{\tau}]$ with continuous density $a(\tau)$ and c.d.f. $A(\tau)$. We continue with the inelastic demand case, assuming the reservation price $\theta>\bar{c}+\bar{\tau}$, so equilibrium market quantity will be unity as all consumers will buy in equilibrium. Assume that firms can perfectly price discriminate and observe the type $\tau$ of each consumer. This simplifies things considerably, as we can determine the Bertrand Equilibrium in each market separately. This structure can be given several interpretations. In terms of the tariff example mentioned earlier, it may simply be the case that different consumers face different tariffs. Or we can interpret this as heterogeneity in transport costs in a spatial context with a Hotelling-like structure. We can

\footnotetext{
${ }^{8}$ Note that there are other forces that act like discounting that will also magnify the impact of switchover disruptions. One example is if there is a small probability each "period" that the market disappears (for example, because of the development of a substitute product).

${ }^{9}$ Another extension (besides the one we consider below) would be for the incumbent, upon adoption, to be able to produce only a certain fraction $y$ of its capacity for a period of time. We could assume during this period it produced at marginal cost $\bar{c}$ (or $\underline{c}$ ), and that once the period is over, it produced at $\underline{c}$.
} 
put the incumbent in the center of a country. Buyers located in the center of the country have high $\tau$ because in addition to paying any tariff they have to incur transportation costs to ship imports inland. Buyers located on the coast have lower $\tau$.

Our results for the Arrow case directly extend to this generalization of the model. Consider the return to adoption in the Arrow case. Let $W_{\text {Arrow;many-markets }}^{S D}$ denote the willingness to pay in the new model (with many markets). To obtain this in the generalized structure, we need only take the return $W_{\text {Arrow }}^{S D}(\tau)$ from (5), which was for a given $\tau$, and integrate over $\tau$,

$$
W_{\text {Arrow;many-markets }}^{S D}=\int_{0}^{\bar{\tau}} a(\tau) W_{\text {Arrow }}^{S D}(\tau) d \tau .
$$

Since from Proposition 1, $W_{\text {Arrow }}^{S D}(\tau)$ is strictly decreasing in $\tau$ for $\tau<\bar{c}-c^{\circ}$ and constant above this, it is immediate that an upward shift in the distribution of $\tau$ (in the sense of first-order stochastic dominance) strictly decreases willingness to pay.

Things are more complex for the Gilbert and Newbery case. Nevertheless, we can use a continuity argument to show that Proposition 4 is robust to adding in a small amount of heterogeneity in $\tau$ so that even right after adoption when the switchover disruption is at its maximum, the incumbent retains some consumers (those with the highest $\tau$ ).

\section{Consumer Dynamics}

Our consumer model features no dynamics. Fixing the prices of the incumbent and all rivals, quantity sold by the incumbent is independent of history. There is a large literature that emphasizes the importance of dynamics on the consumer side. Consumers may bear "switching costs" when they shift from one provider to a second provider. If the consumer goes ahead and makes such a switch, the first provider might have a difficult time getting the consumer back. See Klemperer (1995) for a survey of this literature.

If we introduce these kinds of dynamics on the consumer side, the effects we are isolating here are magnified. We make our point with a stylized example but our point is more general. Suppose that when consumers purchase from a rival, there is some probability they never will come back to the incumbent. Specifically, demand available to the incumbent decays at rate $\delta$ when demand is met by a rival firm. In this case we can rewrite the incumbent's willingness to pay (12) for the innovation in the example at the close of Section 
5 as

$$
W_{G N}^{S D}=e^{-\delta H^{\text {disrupt }}} H^{\text {beyond }}\left(c^{\circ}+\tau-\underline{c}\right)-H^{\text {disrupt }} \tau .
$$

This is the same as (12), except the first term now includes a decay factor for consumers lost over the course of the disruption interval (which has length $H^{\text {disrupt }}$ ). In the original analysis, $\delta=0$ is implicitly assumed. The comparative static that $W_{G N}^{S D}$ decreases in $\tau$ now holds if

$$
e^{-\delta H^{\text {disrupt }}} H^{\text {beyond }}<H^{\text {disrupt }}
$$

For any positive disruption interval $H^{\text {disrupt }}$, the above condition will hold for large enough consumer decay $\delta$.

\section{Uncertainty}

The model is set up with a deterministic cost structure. Often there is a great deal of uncertainty in the adoption of a new technology and this reinforces our point. It may be that a new technology is worse than the existing one, even in the long run, but the only way to find out is to try it. Moreover, once a firm tries it, it may be stuck with it, at least for a substantial period of time. For example, the adoption of a new baggage handling system in the Denver airport turned out to be a mistake, but it took ten years before they abandoned it.

We can capture this with a simple relabeling. Suppose that the model is a static one, in which there is uncertainty about the realization $c$ of a new technology. Assume that if the cost draw ends up $c>c^{\circ}$, the adopting firm is stuck with it - that is, the cost of reverting to the previous technology is prohibitively high. If we simply let $h(c)$ be the density of the cost draw $c$ for the new technology, the model is formally identical to the model studied, and all of our results go through.

\section{Conclusion}

There is a rapidly growing body of evidence that shows firms in more competitive environments are more likely to adopt technologies and increase productivity. This literature includes Trefler (2004), Lewis (2004), Syverson (2004), Symeonidis (2008), Fabrizio, Rose 
and Wolfram (2007), Holmes and Schmitz (2001), Dunne, Klimek and Schmitz (2008) and Schmitz (2005), to name a few.

Our theory can explain some of this evidence. In our theory, a firm that faces a significant decrease in market power may choose to adopt a technology that was widely available for a long time. The reason is that the technology involves some switchover disruption and the opportunity costs of disruption were too high with great market power. Let us close, then, by briefly discussing two episodes where firms, faced with an increase in competition, adopted technologies that had been available beforehand.

Iron Ore Mining. For nearly a century, until the early 1980s, the U.S. and Canadian iron ore industries were the exclusive suppliers to steel plants in the Midwest manufacturing belt (e.g., Chicago and Cleveland). At that time they faced a significant increase in competition in these markets. In response, they adopted a technology that led to a surge in productivity. The technology was a change in organization, in particular, a change in work rules (see, for example, Galdon-Sanchez and Schmitz (2002) and Schmitz (2005)).

Our theory provides an explanation. The firms could have instituted these changes prior to the reduction in market power, but there would have been a switchover disruption, namely, a likely protracted strike by the union. With significant market power, and high iron ore prices, the opportunity costs of lost sales were too high. With the surge in competition, prices and rents fell dramatically. The opportunity costs of a protracted strike were now much lower, and the firms decided to pursue new work rules. Its also quite possible that the firms thought the possibility of a strike, and its duration if it did happen, had fallen as well. But our model predicts this, too, is a force for technology adoption.

Cement Manufacturing. From the end of WWII until the early 1980s, U.S. cement manufacturers faced very little threat of competition from foreign cement producers. In the mid 1980s, cement imports surged, reaching as high as 30 percent of U.S. production in the 1990s. In U.S. states on the coast, or with inland waterway access, the share was even higher. In response to this increase in competition, cement producers adopted a technology that led to a surge in productivity. In fact, TFP in this industry had been falling until the surge in imports, and has since been growing. The technological change, again, was a change in organization (in work rules) (see Dunne, Klimek and Schmitz (2008)). Again, our theory 
provides an explanation.

Overall, while the Arrow theory provides a possible explanation of why monopolies are observed to be sluggish innovators, it does not seem to fit the evidence particularly well. Indeed, monopolists tend to be conservative in a great many ways. And indeed, this makes sense: if you have a good thing going you do not want to rock the boat. The one thing a monopolist fears most is the loss of monopoly. ${ }^{10}$ This is exactly the driving force that explains why switchover disruptions can be so important: a competitor has little to fear from a disruption as they are earning little to begin with. A firm with a lucrative monopoly is well advised not to jeopardize it by adopting a technology that may in the short-run at least, threaten its lucrative position.

\footnotetext{
${ }^{10}$ This is reflected in many contexts. For example, a patent may give nominal control over a technology. But control of the technology itself is more important: it gives effective bargaining power with the legislature, courts and public - "enforce my monopoly or I will not share my technology with you." If you are foolish enough to license your technology and a licensee improves on it, now you are thrown back on the generousity of the legal system. It is the rival who has the effective bargaining power. A fairly good example of this was when the U.S. Navy effectively stripped the Wright Brothers of their monopoly during WWI - a rival with a superior technology left them only with their legal claims, and those proved to be worth little in the face of a government unwilling to enforce them.
} 


\section{Appendix}

\section{Proof of Lemma 1}

Following the notation and formulas found in the proof of Proposition 3, we have

$$
\begin{aligned}
\frac{d v^{S D}}{d \tau}-\frac{d u^{S D}}{d \tau} & =\int_{\underline{c}}^{\min \left\{c^{\circ}+\tau, \bar{c}\right\}} h(c) d c-\int_{\max \left\{c^{\circ}-\tau, \underline{c}\right\}}^{\bar{c}} h(c) d c \\
\frac{d i^{S D}}{d \tau}-\frac{d u^{S D}}{d \tau} & =\int_{\underline{c}}^{\bar{c}} h(c) d c-\int_{\max \left\{c^{\circ}-\tau, \underline{c}\right\}}^{\bar{c}} h(c) d c \\
\frac{d r^{S D}}{d \tau} & =-\int_{\underline{c}}^{\max \left\{c^{\circ}-\tau, \underline{c}\right\}} h(c) d c .
\end{aligned}
$$

Note that at $\tau=0, i^{S D}-u^{S D}=0$, while $v^{S D}-u^{S D}=r^{S D}>0$. Next note for $\tau \in\left(0, \underline{c}-c^{\circ}\right)$, that $i^{S D}-u^{S D}$ is strictly increasing while $r^{S D}$ is strictly decreasing. For $\tau>\underline{c}-c^{\circ}, i^{S D}-u^{S D}$ is weakly increasing, while $r^{S D}$ is flat. Hence if there is ever a point $\tau$ where $i^{S D}-u^{S D}>r^{S D}$, there is a unique cutoff $\tau^{\prime}$ where $i^{S D}-u^{S D}=r^{S D}$, and $i^{S D}-u^{S D}<r^{S D}$ if and only if $\tau<\tau^{\prime}$.

If $c^{\circ}+\tau<\bar{c}$, then the slope of $i^{S D}-u^{S D}$ is strictly greater than the slope of $v^{S D}-u^{S D}$ and otherwise the slope is equal. Hence if there is ever a point $\tau$ where $i^{S D}-u^{S D}>v^{S D}-u^{S D}$, there is a unique cutoff $\tau^{\prime \prime}$ where $i^{S D}-u^{S D}=v^{S D}-u^{S D}$, and $i^{S D}-u^{S D}<v^{S D}-u^{S D}$ if and only if $\tau<\tau^{\prime \prime}$.

If the points $\tau^{\prime}$ and $\tau^{\prime \prime}$ don't exist, then for no $\tau$ is there a strict preference to idle. If both exist, then let $\hat{\tau} \equiv \max \left\{\tau^{\prime}, \tau^{\prime \prime}\right\}$. Q.E.D. 


\section{References}

Anderson, Axel, and Cabral, Luis, "Go for Broke or Play it Safe? Dynamic Competition with Choice of Variance," Rand Journal of Economics, (forthcoming).

Arrow, K. (1962) "Economic Welfare and the Allocation of Resources for Inventions," In The Rate and Direction of Inventive Activity, ed. R. Nelson, Princeton, N.J.: Princeton University Press.

Beer, Michael and Cannon, Mark, "Promise and Peril in Implementing Pay-for-Performance," Human Resources Management, Spring, 2004.

Chari, V.V. and Hopenhayn, Hugo, "Vintage Human Capital, Growth and the Diffusion of New Technology," Journal of Political Economy, vol. 99, pp 1142-65, 1991.

Dunne, Timothy, Klimek, Shawn, and Schmitz, James, A. Jr., "Does Competition Spur Productivity? Evidence From U.S. Cement Manufacturing During the 20th Century," working paper, 2008.

Fabrizio, Kira, and Rose, Nancy, and Wolfram, Catherine, "Do Markets Reduce Costs? Assessing the Impact of Regulatory Restructuring on U.S. Electric Generation Efficiency," American Economic Review September, 2007.

Galdon-Sanchez, Jose Enrique and Schmitz, James, A. Jr. "Competitive Pressure and Labor Productivity: World Iron Ore Markets in the 1980s," American Economic Review 2002.

Gilbert, Richard J. and David M. G. Newbery, (1982) "Preemptive Patenting and the Persistence of Monopoly," The American Economic Review, Vol. 72, No. 3. (Jun., 1982), pp. 514-526.

Ginzberg, Michael, "Early Diagnosis of MIS Implementation Failure: Promising Results and Unanswered Questions," Management Science, Volume 27, Number 4 (April 1981), pp. $459-478$.

Hendricks, Kevin, and Singhal, Vinod, "The Effect of Supply Chain Glitches on Shareholder Wealth," Journal of Operations Management, pp 501-22, 2003.

Hendricks, Kevin, and Singhal, Vinod, "Association between Supply Chain Glitches and Operating Performance," Management Science, May, 2005.

Holmes, Thomas J. and Schmitz, James, A. Jr., "Competition at Work: Railroads vs. Monopoly in the U.S. Shipping Industry," Federal Reserve Bank of Minneapolis Quarterly Review, Spring, 2001.

Huggett, Mark, and Ospina, Sandra "Does productivity growth fall after the adoption of new technology?," Journal of Monetary Economics, pp 173-95, 2001.

Jovanovic, Boyan and Nyarko, Yaw, "Learning by Doing and the Choice of Technology," Econometrica, November, 1996. 
Klemperer, Paul (1995), "Competition when Consumers have Switching Costs: An Overview with Applications to Industrial Organization, Macroeconomics, and International Trade," Review of Economic Studies 62, 515-539.

Klenow, Peter, "Learning Curves and the Cyclical Behavior of Manufacturing Industries," Review of Economic Dynamics, 1998.

Lewis, William. The Power of Productivity. University of Chicago Press, 2004.

Nakamura, Tsuyoshi and Ohashi, Hiroshi, "Technology Adoption, Learning by Doing, and Productivity: A Study of Steel Refining Furnaces," Working Paper, 2005.

Parente, Stephen, "Technology Adoption, Learning-by-doing, and Economic Growth", Journal of Economic Theory, 1994.

Reinganum, Jennifer, "Uncertain Innovation and the Persistence of Monopoly," American Economic Review, September, 1983.

Sakellaris, Plutarchos "Patterns of plant adjustment," Journal of Monetary Economics, pp 425-50, 2004.

Schivardi, Fabiano and Schneider, Martin "Strategic Experimentation and Disruptive Technological Change," Review of Economic Dynamics, (forthcoming, 2008).

Schmitz, James, A. Jr., "What Determines Productivity? Lessons from the Dramatic Recovery of the U.S. and Canadian Iron Ore Industries Following Their Early 1980s Crisis," Journal of Political Economy, June, 2005.

Schmutzler, Armin, "The Relation between Competition and Innovation - Why Is It Such a Mess?" University of Zurich, mimeo, November, 2007.

Speier, Cheri and Venkatesh, Viswanath, "The Hidden Minefields in the Adoption of Sales Force Automation Technologies," Journal of Marketing, July, 2002.

Symeonidis, George, "The Effect of Competition on Wages and Productivity: Evidence from the UK", Review of Economics and Statistics, vol. 90 (2008), pp. 134-146

Syverson, Chad. "Market Structure and Productivity: A Concrete Example," Journal of Political Economy, 2004.

Tirole, Jean, (1988) The Theory of Industrial Organization, Cambridge, MA: The MIT Press.

Trefler, Daniel, "The Long and Short of the Canada-U.S. Free Trade Agreement," American Economic Review, September, 2004.

Vives, Xavier, "Innovation and Competitive Pressure," Journal of Industrial Economics (forthcoming). 
Figure 1

An Example of a Cost Structure with Switchover Disruption

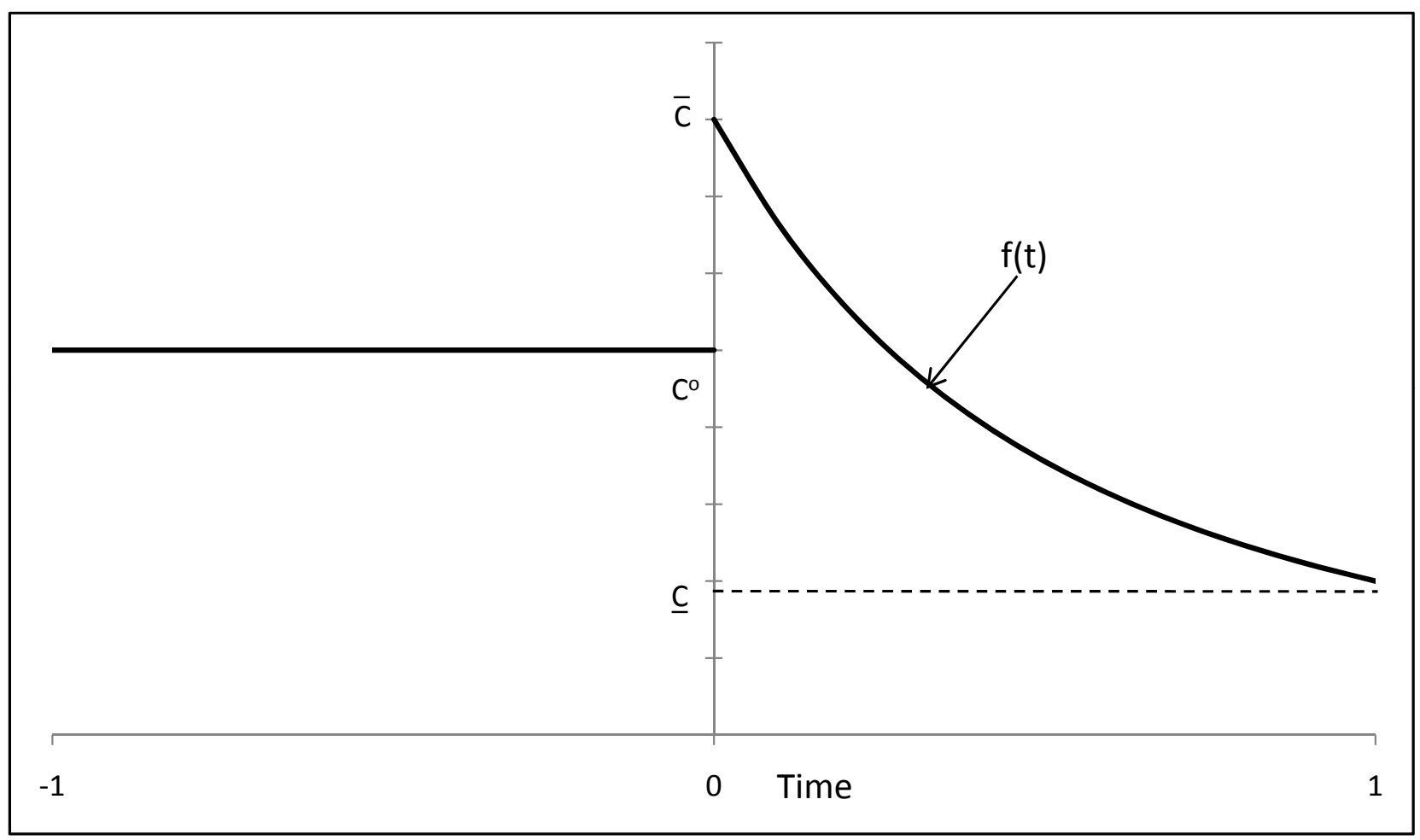


Figure 2

The Incentives to Adopt with Small and Large Switchover Disruption

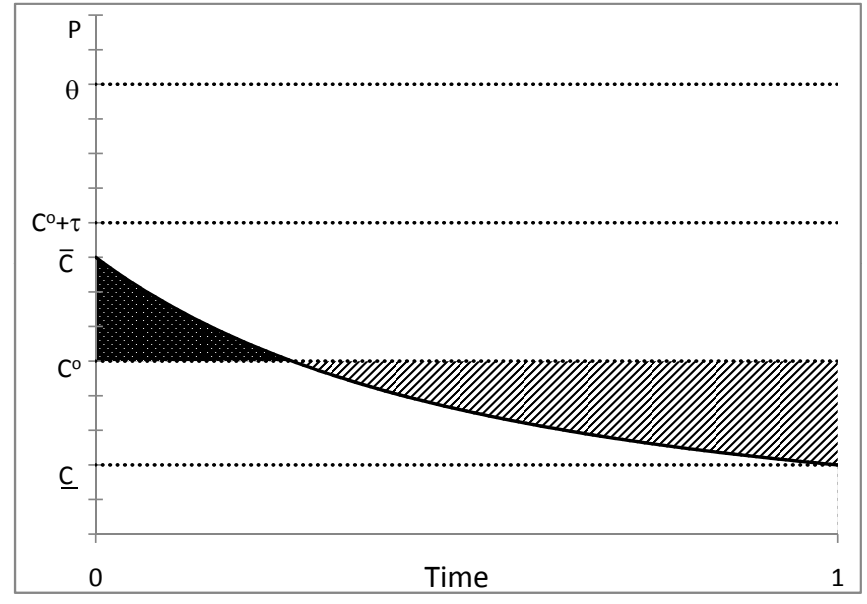

(a) Small Switchover Disruption

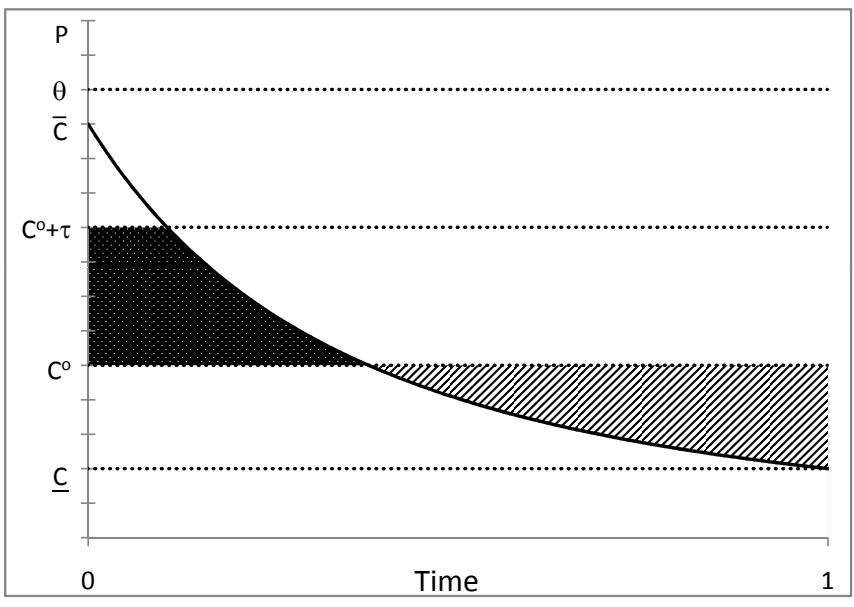

(b) Large Switchover Disruption 